\title{
Ruptured rudimentary horn of the unicornuate uterus at 16 weeks of pregnancy: a case report
}

\author{
Sunil Kumar K S*, Laxmi Vijay Yaliwal, Apurva Amarnath, Prajna Anchan
}

\begin{abstract}
Department of Obstetrics and Gynecology, SDM College of Medical Sciences and Hospital, Sattur, Dharwad,
\end{abstract} Karnataka, Pin 580009, India

Received: 6 April 2013

Accepted: 14 April 2013

*Correspondence:

Dr. Sunil Kumar K S,

E-mail: drsuneelks@yahoo.com

(C) 2013 Sunilkumar KS et al. This is an open-access article distributed under the terms of the Creative Commons Attribution License, which permits unrestricted use, distribution, and reproduction in any medium, provided the original work is properly cited.

\begin{abstract}
Pregnancy in the rudimentary horn of the uterus is a rare form of ectopic pregnancy; most of the cases were being diagnosed at laparotomy for haemorrhagic shock due to rupture when the patient presents in the second trimester. Prerupture diagnosis is possible in the early pregnancy in suspicious cases. Pregnancy in the rudimentary horn has a poor maternal and foetal outcome and $90 \%$ of them present with intraperitoneal haemorrhage in the second trimester due to rupture of the horn. We report a case of ruptured rudimentary horn pregnancy at 16 weeks, in shock with severe anaemia. Excision of the rudimentary horn with right salpingectomy was done.
\end{abstract}

Keywords: Unicornuate uterus, Rudimentary horn pregnancy, Prerupture diagnosis

\section{INTRODUCTION}

The incidence of mullerian duct anomalies in general population is found to be $3.2 \%$. Unicornuate uterus occurs in 1 in 4020 women in the general population and a rudimentary horn is present in about $84 \%$ of the cases. ${ }^{1}$ Most of these rudimentary horns are non-communicating. Ectopic pregnancy occurring in a non-communicating rudimentary horn has an estimated incidence of 1 per 100,000 to 140,000 pregnancies. ${ }^{2}$ Pregnancy in the rudimentary horn usually culminates in rupture during second trimester in about $90 \%$ of the cases. Pre-rupture diagnosis is unusual and challenging but possible with high index of suspicion in the early pregnancy. We report a case of ruptured rudimentary horn pregnancy who presented in the second trimester.

\section{CASE REPORT}

A 22 year old primigravida at 16 weeks of gestation, presented with severe abdominal pain for 6 hours prior to admission. On examination, she was found to be in hypovolemic shock with tachycardia, feeble pulse, blood pressure of 90/40 $\mathrm{mmHg}$ and cold extremities with pallor. Abdomen was distended, with guarding and rigidity and tenderness in lower abdomen. Per vaginal examination showed cervical motion tenderness, fullness in the fornices and tender suprapubic mass measuring 18 weeks gravid uterus. There was no vaginal bleeding.

Her haemoglobin on admission was 3.9gm\%. Ultrasound abdomen showed gross ascites. Right adnexal mass or secondary abdominal ectopic pregnancy measuring $57 \mathrm{X} 20 \mathrm{~mm}$ with live foetus of 17 weeks of gestation was noted. Uterus was enlarged and partially ruptured. The patient was taken up for emergency laparotomy after initial resuscitation with a provisional diagnosis of ruptured corneal ectopic pregnancy.

Intra-operatively there was 1.5 liters of haemoperitoneum and 500grams clots. Foetus with placenta of 16 weeks gestation with intact membranes was seen partially lying 
outside the ruptured superior margin of the rudimentary horn. There was active bleeding from the margins. Normal uterus was seen lying on the left side of the rudimentary horn with normal left ovary and left fallopian tube. The right ovary was normal. Right fallopian tube was normal in length and attached to rudimentary horn. Sigmoid colon was densely adherent to the rudimentary horn.

Excision of rudimentary horn with ipsilateral salpingectomy was done. Patient was maintained on mechanical ventilation for 10 hours post operatively in the surgical intensive care unit. Two units of blood were transfused. She was discharged healthy on $7^{\text {th }}$ postoperative day, with haemoglobin of $9.5 \mathrm{gm} \%$.

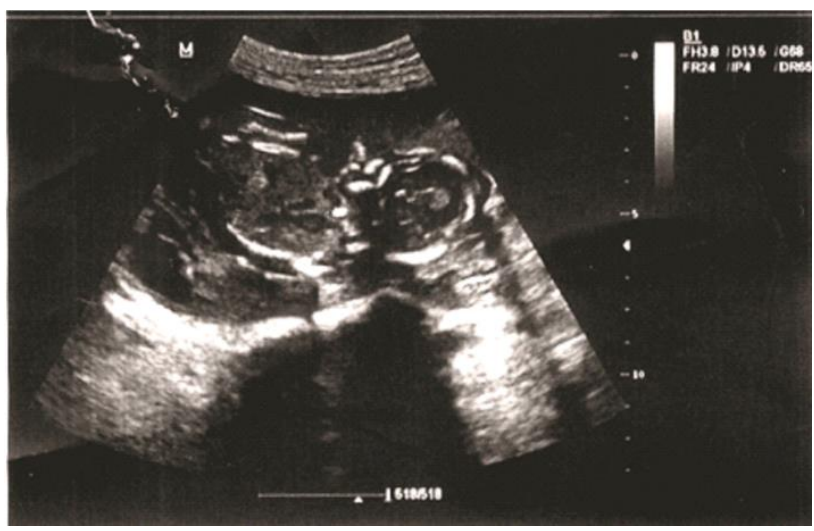

Figure 1: Ultrasound picture showing live foetus with partial rupture of the uterus.

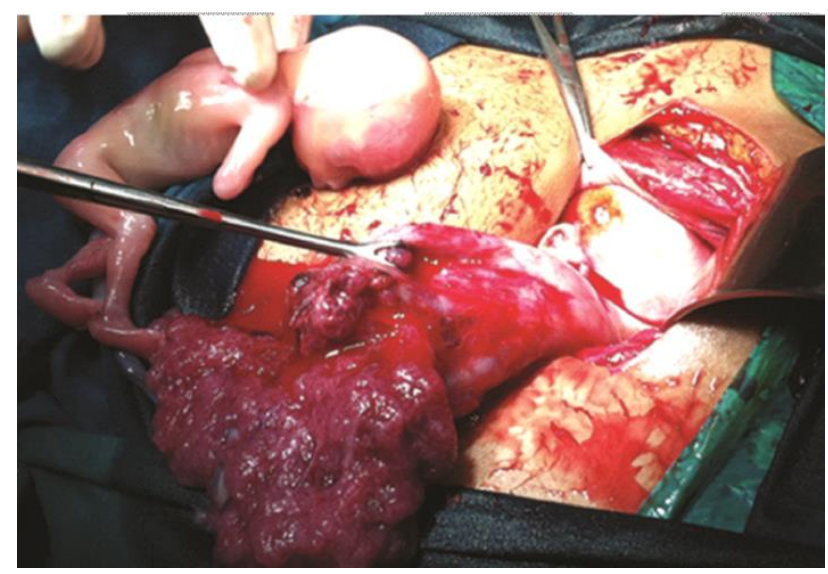

Figure 2: Ruptured rudimentary horn with placenta and foetus, with normal uterus on its left side.

\section{DISCUSSION}

Unicornuate uterus results from the failure in the development of one of the paramesonephric ducts, either partially or completely. Partial development of one of the ducts gives rise to a rudimentary uterine horn. As per of the revised classification for Mullerian anomalies given by American society of reproductive medicine, unicornuate uterus is a type 2 classification with unilateral hypoplasia or agenesis. It can be further subclassified in to communicating, non-communicating, no cavity, and no horn. ${ }^{1}$

Pregnancy in a non-communicating rudimentary horn occurs through the transperitoneal migration of the spermatozoon or the fertilized ovum, as evidenced by the $8 \%$ prevalence of a corpus luteum on the side contralateral to the rudimentary horn containing the pregnancy. $^{2}$ In most of the cases the pregnancy in the rudimentary horn leads to spontaneous abortion, preterm labour, intrauterine growth restriction or foetal demise. ${ }^{1}$ The most dreaded complication is the massive intraperitoneal haemorrhage due to rupture of the horn which can be life threatening to the mother.

The usual outcome of the rudimentary horn pregnancy is rupture in the second trimester in about $90 \%$ of the cases with foetal demise which can be catastrophic. ${ }^{2}$ Unlike tubal ectopic pregnancy, bleeding is more severe in rupture of the rudimentary horn, the uterine wall is much thicker and more vascular. The uterine rupture associated with rudimentary horn was first reported in 1669 by Mauriceau. ${ }^{3}$ The timing of rupture varies from 5 to 35 weeks depending on the horn musculature and its ability to hypertrophy and dilate. Maternal mortality due to rupture was $47.6 \%$ before 1900 but no case of maternal death has been reported since $1960 .{ }^{4}$ Few cases of pregnancies with late or false diagnosis were progressed to third trimester resulting in live births have been reported. ${ }^{5}$ Among these neonatal survivability was only $6 \%$. $^{5}$

As the consequences of rupture can cause significant mortality and morbidity, early diagnosis is essential for management. However the pre-rupture diagnosis of rudimentary horn pregnancy is challenging. A careful ultrasound in the first trimester with a high index suspicion, one should be able to make a diagnosis of pregnancy in the rudimentary horn. Tsafrir et al has proposed a set of criteria for diagnosing pregnancy in the rudimentary horn: (1) a pseudo pattern of asymmetrical bicornuate uterus; (2) absent visual continuity tissue surrounding the gestation sac and the uterine cervix; (3) presence of myometrial tissue surrounding the gestational sac. $^{6}$ The sensitivity of ultrasound is only $26 \%$ and sensitivity decreases as the pregnancy advances. ${ }^{7}$ In such cases Magnetic resonance imaging (MRI) is very useful not only in confirming the diagnosis, it also helps to plan the surgery. ${ }^{8}$ Tubal pregnancy, cornual pregnancy, and abdominal pregnancy are common sonographic and clinical misdiagnosis. ${ }^{4}$ It is very difficult establish diagnosis in second trimester due to lack of definitive clinical criteria.

The traditional and established treatment for rudimentary horn pregnancy is surgical removal of the pregnant horn even in unruptured case to prevent rupture and recurrent rudimentary horn pregnancy. ${ }^{4}$ We performed an emergency laparotomy and successfully excised the rudimentary horn along with ipsilateral salpingectomy. 
Laparoscopic excision of the rudimentary horn pregnancy prior to rupture has been done successfully since last two decades. ${ }^{9,10}$ Renal anomalies are found in $36 \%$ of cases; hence it is mandatory to assess these women prior to surgery and if required better to do ureterolysis before the excision of the horn. ${ }^{1}$ Medical management with methotrexate during early pregnancy in the rudimentary horn has also been used successfully. ${ }^{11}$

\section{CONCLUSION}

Rudimentary horn pregnancy is a rare complication which carries grave risk to the mother. More than $90 \%$ of the cases present in second trimester with intraperitoneal haemorrhage due to rupture of the horn. Diagnosis prior to rupture should be the concern in early pregnancy with either ultrasound or MRI to prevent life threatening complications. The recent trend is to do laparoscopic excision of the rudimentary horn; laparotomy is still an option when the patient is in shock.

\section{Funding: None}

Competing interests: None declared

Ethical approval: Not required

\section{REFERENCES}

1. Reichman D, Laufer MR, Robinson BK. Pregnancy outcomes in unicornuate uteri: a review. Fertil Steril 2009;91:1886-94.

2. O'Leary JL, O'Leary JA. Rudimentary horn pregnancy. Obstet Gynecol 1963;22:371-5.
3. Mauriceau F. Traite des maladies des femmes Grosses vol. 1, Compaigne des libraries, Paris, France, 1721.4.

4. Nahum GG. Rudimentary uterine horn pregnancy. The $20^{\text {th }}$-century worldwide experience of 588 cases. J Reprod Med 2002;47:151-63.

5. Shin JW, Kim HJ. Case of live birth in a noncommunicating rudimentary horn pregnancy. J Obstet Gynaecol Res 2005;31:329-31.

6. Tsafrir A, Rojansky N, Sela HY, Gomori JM, Nadjari M. Rudimentary horn pregnancy: firsttrimester prerupture sonographic diagnosis and confirmation by magnetic resonance imaging. J Ultrasound Med 2005;24:219-23.

7. Jayasinghe Y, Rane A, Stalewski H, Grover S. The presentation and early diagnosis of the rudimentary uterine horn. Obstet Gynecol 2005;105:1456-67.

8. Lawhon BP, Wax JR, Dufort RT. Rudimentary uterine horn pregnancy diagnosed with magnetic resonance imaging. Obstet Gynecol 1998;91(5 Pt 2):869.

9. Yan CM. Laparoscopic management of three rare types of ectopic pregnancy. Hong Kong Med J 2010;16:132-6.

10. Sharma D, Usha MG, Gaikwad R, Sudha S. Laparoscopic resection of unruptured rudimentary horn pregnancy. Int $\mathbf{J}$ Reprod Contracept Obstet Gynecol 2013;2:95-8.

11. Edelman AB, Jensen JT, Lee DM, Nichols MD. Successful medical abortion of a pregnancy within a noncommunicating rudimentary uterine horn. Am J Obstet Gynecol 2003;189:886-7.

DOI: $10.5455 / 2320-1770 . i j r \operatorname{cog} 20130633$

Cite this article as: Sunilkumar KS, Yaliwal LV, Amarnath A, Anchan P. Ruptured rudimentary horn of the unicornuate uterus at 16 weeks of pregnancy: a case report. Int J Reprod Contracept Obstet Gynecol 2013;2:248-50. 